\title{
Studies on Hemoglobin Biosynthesis: Asynchronous Synthesis of Hemoglobin A and Hemoglobin A2 by Erythrocyte Precursors*
}

\author{
Ronald F. Rieder and David J. Weatherall \\ (From the Department of Medicine, The Johns Hopkins University School of Medicine and \\ Hospital, Baltimore, $M d$.)
}

Hemoglobin $\mathrm{A}_{2}$ comprises less than $3.3 \%$ of the total hemoglobin of normal adults $(1,2)$. Elevated levels are found in many individuals with thalassemia minor $(3,4)$, in some patients with pernicious anemia in relapse (5), and in persons heterozygous for hemoglobin Zürich (6). Reduced levels are encountered in the newborn child (3), in some patients with anemia due to iron deficiency (5), and in persons with hereditary persistence of fetal hemoglobin $(7,8)$. In the study to be described, measurements were made of the relative rates of synthesis of hemoglobins $A$ and $A_{2}$ by red cell precursors of patients with certain hematologic disorders.

\section{Methods}

Blood samples were drawn into tubes containing heparin, $0.2 \mathrm{mg}$ per $\mathrm{ml}$. Experiments were initiated within 2 hours except that blood from two patients with thalassemia major was transported in cooled containers and studied within 5 hours.

Measurement of hemoglobin. The concentrations of hemoglobin solutions were compared by measuring optical densities of oxyhemoglobin at $415 \mathrm{~m} \mu$ of cyanmethemoglobin or cyanhematin (9) at $543 \mathrm{~m} \mu$.

Synthesis of hemoglobins $A$ and $A_{2}$ by reticulocytes in vitro. Hemoglobin synthesis by reticulocytes in vitro was studied by incubating cells with $\mathrm{Fe}^{50}$ citrate $(1 \mu \mathrm{g}$ of $\mathrm{Fe}$ per $\mathrm{ml}$; initial specific activity, approximately 30 $\mu \mathrm{c}$ per $\mathrm{mg}$ ) or uniformly labeled leucine- $\mathrm{C}^{14}$ (specific activity, $0.10 \mu \mathrm{c}$ per $0.0348 \mathrm{mg}$ ) and measuring the specific activities of the purified hemoglobin fractions.

In experiments employing radioactive iron, $1 \mathrm{ml}$ of $\mathrm{Fe}^{50}$ citrate $(8$ to $30 \mu \mathrm{c}$ ) was incubated with $4 \mathrm{ml}$ of a type $A B$ human serum having a high iron-binding capacity. The final incubation medium was made by adding the $\mathrm{Fe}^{50}$ serum to $5 \mathrm{ml}$ of a modified Krebs-Henseleit

* Submitted for publication June 11, 1964; accepted September 11, 1964.

Part of this work has been published in abstract form (J. clin. Invest. 1964, 43, 1237).

This work was aided by U. S. Public Health Service research grant HE 02799. solution containing glucose, amino acids, penicillin G, and streptomycin sulfate as described by Borsook (10). Ferrous sulfate was omitted.

In experiments employing leucine- $\mathrm{C}^{14}$ the final incubation medium was made by drying samples $(0.5$ to $1 \mathrm{ml})$ of a solution of uniformly labeled leucine- $\mathrm{C}^{14}$ containing $100 \mu \mathrm{c}$ per $\mathrm{ml}$ (representing $348 \mu \mathrm{g}$ of leucine) in the incubation flask and then adding 4 to $8 \mathrm{ml}$ of leucinefree modified Krebs-Henseleit solution without serum.

Reticulocyte-rich heparinized blood was centrifuged, and the plasma, leukocytes, and platelets were removed. The red cells were washed three times with $0.85 \% \mathrm{NaCl}$; then 1 vol of cells was added to 2 to 4 vol of incubation mixture. The cells were incubated at $37^{\circ} \mathrm{C}$ in a Dubnoff-type shaking water bath. The incubation was terminated at times ranging from $30 \mathrm{~min}$ utes to 20 hours. In some cases the rate of synthesis of each hemoglobin fraction was studied by removing samples from the incubation flask at various time intervals.

In experiments employing radioactive iron, the reaction was stopped by adding the mixture to $\frac{1}{2}$ vol of cold $0.1 \mathrm{~N} \mathrm{KCN}$. The red cells were washed five times with several volumes of $0.85 \% \mathrm{NaCl}$ and then lysed by shaking with distilled water and carbon tetrachloride. Stromal material was removed by low speed centrifugation, and the cleared hemolysate was further centrifuged at $25,000 \mathrm{~g}$ for 1 hour. The hemolysate was dialyzed for several days against large volumes of $0.85 \% \mathrm{NaCl}$ with many changes of the outside fluid.

In experiments employing leucine- $\mathrm{C}^{14}$ the incubation was stopped by freezing and thawing. Stromal material was removed by centrifugation, and then free leucine was removed by passing the hemoglobin solution through a column of Sephadex G-25 1 equilibrated with the chromatographic developer to be used in the subsequent separation of hemoglobin fractions. The complete removal of free leucine by this technique was confirmed by experiments in which, following passage through Sephadex, the hemolysate was dialyzed against large volumes of $0.85 \% \mathrm{NaCl}$ with many changes of the outside fluid and no loss of radioactivity.

Preparation of hemoglobins $A$ and $A_{\mathrm{s}}$. In all experiments utilizing leucine- $\mathrm{C}^{14}$ and in some experiments utilizing $\mathrm{Fe}^{\mathrm{se}}$, hemoglobin fractionation was performed by

\footnotetext{
1 Pharmacia, Uppsala, Sweden.
} 


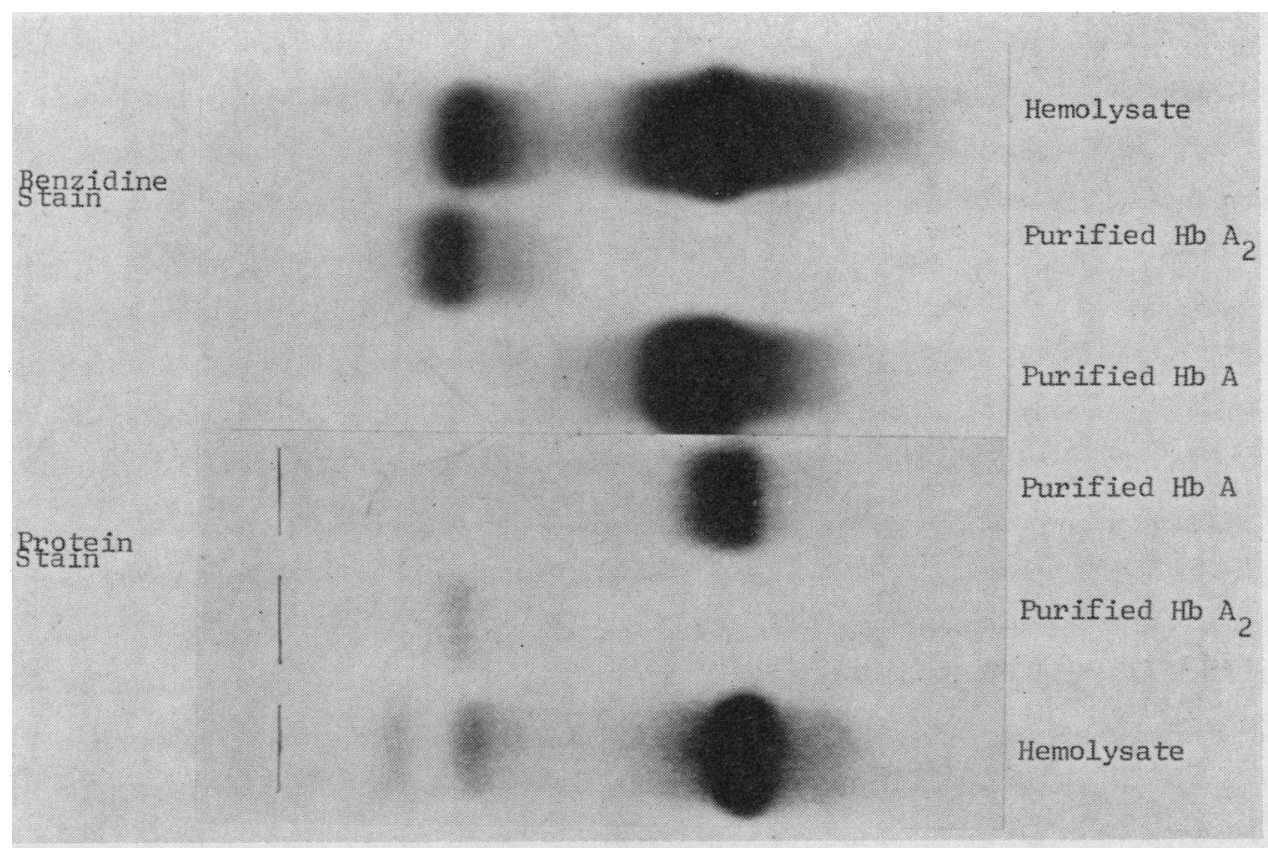

Fig. 1. Starch Gel electrophoresis at PH 8.6. The Figure shows the results of electrophoresis of purified hemoglobins $(\mathrm{Hb}) \mathrm{A}$ and $\mathrm{A}_{2}$ and the cleared hemolysate from which the fractions were derived. The upper pattern was stained with benzidine and the lower pattern with amido black 10B.

initial column chromatography on Amberlite CG-50 followed by starch block and starch gel electrophoresis. In the remainder of the experiments utilizing $\mathrm{Fe}^{50}$, separation was achieved by starch block electrophoresis alone.

Twenty- $\times 1-\mathrm{cm}$ columns were equilibrated at $4^{\circ} \mathrm{C}$ for several days against Developer IV or VI $(11,12)$, and 70 to $100 \mathrm{mg}$ of hemoglobin in $1-\mathrm{ml}$ vol was ap- plied. After elution of the nonhemoglobin proteins and, in some cases, hemoglobin F I (11), the column was equilibrated at $28^{\circ}$ and any hemoglobin F II eluted, followed by hemoglobins $A$ and $A_{2}$. In some experiments hemoglobins $A$ (or $S$ ) and $A_{2}$ were eluted as a single peak by the passage of $0.3 \mathrm{M}$ sodium phosphate buffer, $\mathrm{pH}$ 7.6. After chromatography the fractions were dialyzed against water and concentrated by ultrafiltration.

TABLE I

Incorporation of $\mathrm{Fe}^{59}$ into hemoglobin fractions by reticulocytes in vitro (hemoglobins $A$ and $A_{2}$ separated by starch block electrophoresis)*

\begin{tabular}{|c|c|c|c|c|c|c|c|c|c|}
\hline \multirow[b]{2}{*}{ Patient } & \multirow[b]{2}{*}{ Diagnosis } & \multirow[b]{2}{*}{$\mathrm{Hb}$} & \multirow[b]{2}{*}{ Hct } & \multirow[b]{2}{*}{ Retic } & \multirow[b]{2}{*}{$\mathrm{Hb} \mathrm{A}_{2}$} & \multirow{2}{*}{$\begin{array}{l}\text { Incuba- } \\
\text { tion } \\
\text { time }\end{array}$} & \multicolumn{2}{|c|}{ Specific activity } & \multirow[b]{2}{*}{ Ratio SA A/A2 } \\
\hline & & & & & & & Hb A & $\mathrm{Hb} \mathrm{Az}$ & \\
\hline \multicolumn{2}{|c|}{ Reticulocyte preparations } & $\mathrm{g} / 100 \mathrm{ml}$ & $\%$ & $\%$ & $\%$ & hours & \multicolumn{2}{|c|}{$c p m / m g$} & \\
\hline $\begin{array}{l}\text { A. B. } \\
\text { R. R. } \\
\text { G. R. } \\
\text { L. Y. } \\
\text { J. Y. } \\
\text { M. W. } \\
\text { I. W. } \\
\text { O. P. } \\
\text { W. C. } \\
\text { P. K. } \\
\text { F. S. } \\
\text { D. W. } \\
\text { M. J. }\end{array}$ & $\begin{array}{l}\text { Ovalocytosis } \\
\text { Spherocytosis } \\
\text { Zieve's syndrome } \\
\text { Pyruvate kinase deficiency } \\
\text { Pyruvate kinase deficiency } \\
\text { Iron deficiency } \\
\text { Iron deficiency } \\
\text { Iron deficiency } \\
\text { Folic acid deficiency } \\
\text { Pernicious anemia } \\
\text { Pernicious anemia } \\
\text { Myeloid metaplasia } \\
\text { Sickle-cell anemia }\end{array}$ & $\begin{array}{r}11.4 \\
12.4 \\
8.2 \\
10.6 \\
4.3 \\
7.8 \\
7.3\end{array}$ & $\begin{array}{l}36 \\
33.4 \\
28.2 \\
34.3 \\
28 \\
16.7 \\
27.2 \\
29 \\
22.6 \\
17.2 \\
17 \\
25 \\
31.8\end{array}$ & $\begin{array}{r}5.1 \\
8.0 \\
12.2 \\
15.6 \\
42.2 \\
7.1 \\
13.2 \\
15.6 \\
22.5 \\
28.6 \\
19.3 \\
8\end{array}$ & $\begin{array}{l}2.7 \\
2.2 \\
2.5 \\
3.0 \\
2.5 \\
1.9 \\
2.3 \\
1.9 \\
2.5 \\
3.2 \\
3.2 \\
3.6\end{array}$ & $\begin{array}{c}6 \\
4.5 \\
21 \\
5.3 \\
7 \\
17.5 \\
21.3 \\
21.5 \\
4 \\
20 \\
21 \\
5 \\
15.3\end{array}$ & $\begin{array}{l}81: 6 \\
10.9 \\
86.4 \\
16.0 \\
257 \\
218 \\
362 \\
360 \\
123 \\
244 \\
526 \\
673 \\
15.5(\mathrm{~S})\end{array}$ & $\begin{array}{c}38.6 \\
5.8 \\
40 \\
8.4 \\
141 \\
74 \\
179 \\
316 \\
72 \\
103 \\
211 \\
325 \\
6.9\end{array}$ & $\begin{array}{l}2.1 \\
1.9 \\
2.2 \\
1.9 \\
1.8 \\
2.9 \\
2.0 \\
1.1 \\
1.7 \\
2.4 \\
2.5 \\
2.1 \\
2.2\left(\mathrm{~S} / \mathrm{A}_{2}\right)\end{array}$ \\
\hline
\end{tabular}

$* \mathrm{Hb}=$ hemoglobin, Hct $=$ hematocrit, and retic $=$ reticulocytes. 
Hemoglobins $A$ and $A_{2}$ were further purified by starch block electrophoresis using barbital buffer, $\mathrm{pH}$ 8.6 (3). Hemoglobins $\mathrm{A}, \mathrm{S}$, and $\mathrm{A}_{2}$ were separated by starch gel electrophoresis $(13,14)$, individual bands being cut out and placed in slots in a starch block. After elution from starch block each fraction was concentrated, dialyzed against $0.001 \mathrm{M}$ phosphate buffer, $\mathrm{pH} 7.0$, and its purity checked by starch gel electrophoresis (Figure 1).

Measurement of radioactivity in hemoglobin fractions. $\mathrm{Fe}^{5 \theta}$ radioactivity was measured in hemoglobin solutions of known volume and concentration with a 5- or 3-inch well-type $\mathrm{NaI}$ solid crystal scintillation counter. A 1.05Mev base line with a $100-\mathrm{Kev}$ window was employed.

For measurement of leucine- $\mathrm{C}^{14}$, known amounts of hemoglobin of approximately $0.5 \mathrm{mg}$ in 0.1 - or $0.2-\mathrm{ml}$ vol were dried on aluminum planchets. The dried material was then redissolved and spread with a few drops of $91 \%$ formic acid and dried again as a thin spot in the center of the planchet. By this method the necessity for correction for self-absorption was avoided (15).

Enough sample and background counts were taken to assure a sample per cent error of less than $5 \%$.

\section{Results}

Incorporation of $F e^{59}$ into hemoglobins $A$ and $A_{2}$ by reticulocytes in vitro. Table $I$ indicates the results of 13 experiments in which blood from individuals with a variety of clinical conditions was incubated with radioactive iron for periods ranging from 4 to 21 hours. In each case hemoglobins $\mathrm{A}$ and $\mathrm{A}_{2}$ were separated by starch block electrophoresis without initial column chromatography. In every experiment except one, the specific activity of hemoglobin $\mathrm{A}$ was approximately twice that of hemoglobin $A_{2}$. The relative specific activities of hemoglobins $A$ and $A_{2}$ were not related to the number of reticulocytes in the incubation mixture.

To rule out the possibility that hemoglobin $\mathrm{A}$

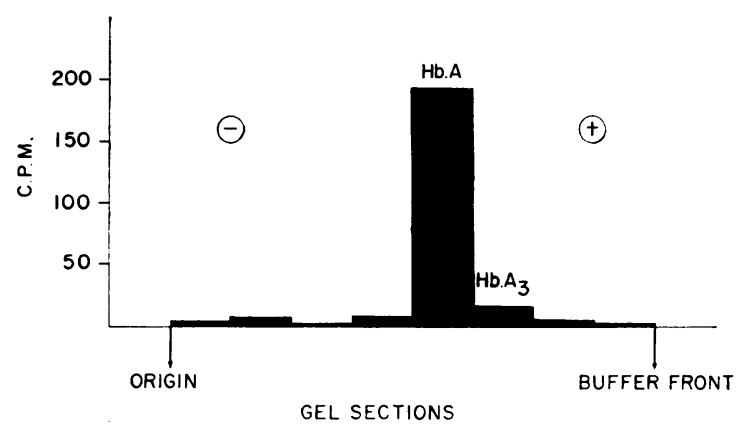

Fig. 2. Distribution of $\mathrm{FE}^{59}$ Radioactivity along THE STARCH GEL. Radioactive hemoglobin A eluted from a starch block electrophoretic run was subjected to starch gel electrophoresis. The gel was cut in sections and the radioactivity measured in each section. Significant radioactivity was found only in the area of hemoglobin A.

separated by starch block was contaminated with a radioactive protein, two types of experiments were performed. Erythrocytes from a patient with pyruvate kinase deficiency (J. Y., Table I) were incubated with $\mathrm{Fe}^{59}$, and hemoglobin $\mathrm{A}$ was separated by starch block electrophoresis. The eluted hemoglobin was subjected to starch gel electrophoresis, the gel sectioned, and the radioactivity of each section determined (Figure 2). No significant radioactivity was detected in any section other than that containing the hemoglobin A band. To exclude contamination of hemoglobin A by an iron-containing nonheme protein (16), the specific activities of hemoglobins $A$ and $A_{2}$ were measured in four experiments in which the nonheme proteins were removed by initial column chromatography (Table II). In each case the specific activity of hemoglobin $\mathrm{A}$ was greater than that of hemoglobin $\mathrm{A}_{2}$.

TABLE II

Incorporation of $F^{59}$ into hemoglobin by reticulocytes

(hemoglobins $A$ and $A_{2}$ separated by column chromatography followed by starch block electrophoresis)*

\begin{tabular}{|c|c|c|c|c|c|c|c|c|}
\hline \multirow[b]{2}{*}{ Patient } & \multirow[b]{2}{*}{ Diagnosis } & \multirow[b]{2}{*}{ Hct } & \multirow[b]{2}{*}{ Retic } & \multirow[b]{2}{*}{$\mathrm{Hb} \mathrm{A}_{2}$} & \multirow{2}{*}{$\begin{array}{c}\text { Incu- } \\
\text { bation } \\
\text { time }\end{array}$} & \multicolumn{2}{|c|}{ Specific activity } & \multirow[b]{2}{*}{ Ratio SA A/A2 } \\
\hline & & & & & & $\mathrm{Hb} \mathrm{A}$ & $\overline{\mathrm{Hb} \mathrm{A}}$ & \\
\hline \multicolumn{2}{|c|}{ Reticulocyte preparations } & $\%$ & $\%$ & $\%$ & hours & \multicolumn{2}{|c|}{$c p m / m g$} & \\
\hline $\begin{array}{l}\text { J. P. } \\
\text { M. B. } \\
\text { J. } . \mathbf{W} . \\
\text { J. N. }\end{array}$ & $\begin{array}{l}\text { Pernicious anemia } \\
\text { Pernicious anemia } \\
\text { Folic acid deficiency } \\
\text { Sickle-cell anemia }\end{array}$ & $\begin{array}{l}29.9 \\
22.8 \\
25 \\
25\end{array}$ & $\begin{array}{l}9 \\
50 \\
28 \\
16.8\end{array}$ & $\begin{array}{l}2.7 \\
3.8\end{array}$ & $\begin{array}{l}5 \\
5 \\
4.5 \\
5\end{array}$ & $\begin{array}{l}19.3 \\
58 \\
55 \\
112(\mathrm{~S})\end{array}$ & $\begin{array}{l}6.7 \\
21 \\
30.9 \\
51.8\end{array}$ & $\begin{array}{l}2.9 \\
2.8 \\
1.8 \\
2.2\left(\mathrm{~S} / \mathrm{A}_{2}\right)\end{array}$ \\
\hline
\end{tabular}

* See footnote to Table I for abbreviations. 


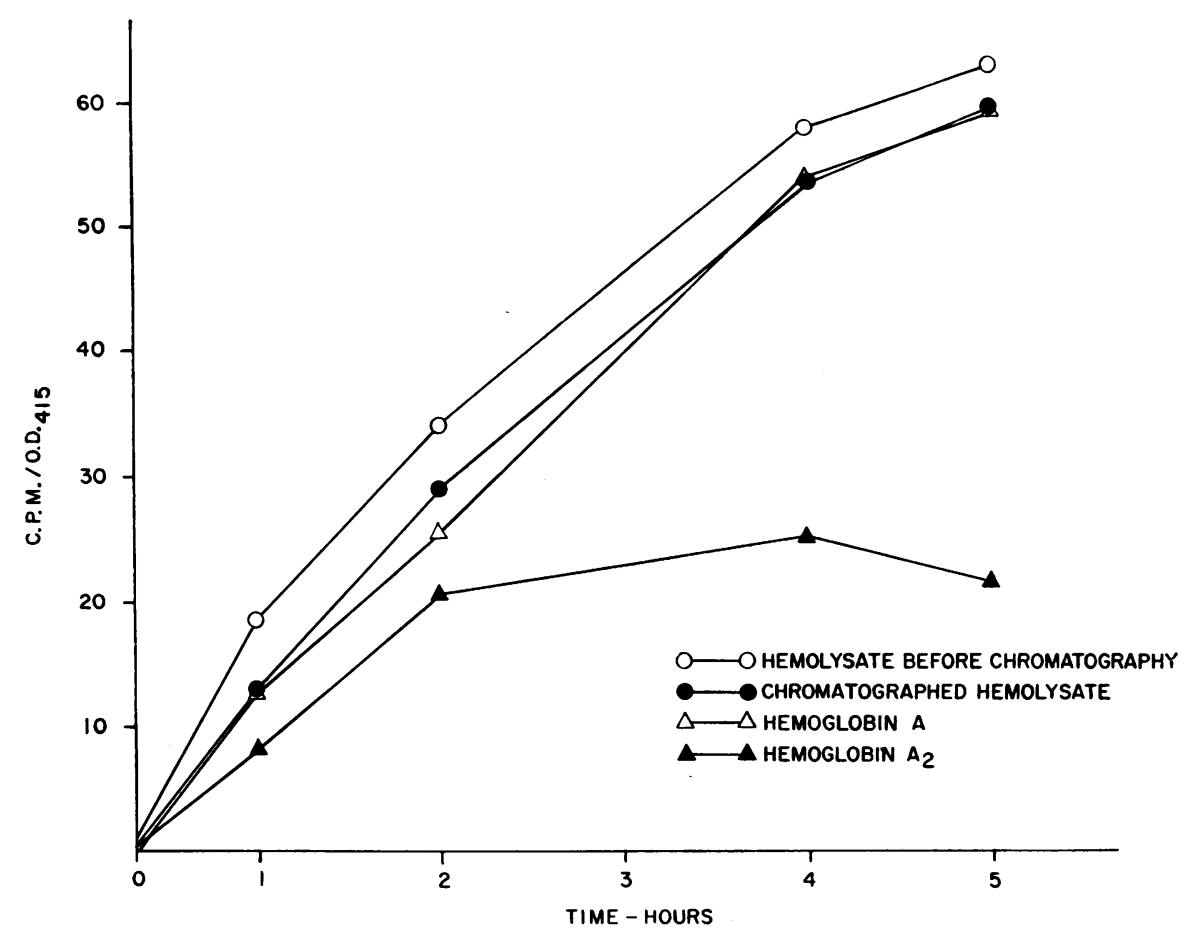

Fig. 3. InCORPORATION OF $\mathrm{FE}^{\mathrm{D}}$ BY RETICULOCYTES. The rise in the specific activities is shown for the hemolysate before and after chromatography and for the purified hemoglobins $A$ and $A_{s}$ fractions.

Figure 3 shows the results of an experiment in which blood was incubated for 5 hours with radioactive iron, samples being withdrawn at various times and studied before and after column chromatography. In each case the specific activity of hemoglobin $\mathrm{A}_{2}$ was lower than that of hemoglobin $\mathrm{A}$ or of the whole hemolysate, the differences in specific activities becoming more marked with time of incubation.

Incorporation of $F e^{59}$ into hemoglobins $A$ and $A_{2}$ in vivo. Patient R. R. (Table I) was given an intravenous injection of $10 \mu \mathrm{c}$ of $\mathrm{Fe}^{59}$. Blood was collected on the fifth and sixth days after administration. Hemoglobins $\mathrm{A}$ and $\mathrm{A}_{2}$ were separated, and the radioactivity in each fraction was determined. The specific activities of hemoglobins $A$ and $A_{2}$ on day 5 were 2.7 and 2.8 and on day $6,2.6$ and 2.6 , cpm per $\mathrm{mg}$, respectively. The specific activities of hemoglobins $A$ and $A_{2}$ were almost identical, indicating that synthesis of these two fractions was proportional to the peripheral blood concentrations.

Incorporation of $F e^{59}$ into hemoglobins $S$ and $A_{2}$ by reticulocytes in vitro. Two experiments were done with the blood of patients having sickle-cell anemia. The results are shown in Tables I and II. Hemoglobin S had a higher specific activity than hemoglobin $A_{2}$ in both experiments.

In the experiments with the blood of patient J. N. (Table II), a portion of the cells was re-

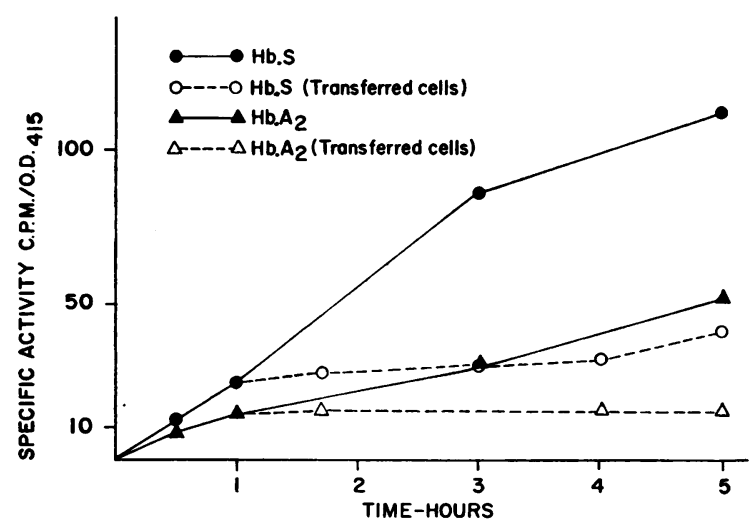

Fig. 4. Incorporation of $F^{\infty 0}$ into hemoglobins $S$ AND $A_{2}$ BY RETICULOCYTEs. The specific activities of hemoglobins $S$ and $A_{2}$ are shown for cells incubated with $\mathrm{Fe}^{\infty}$ for 5 hours and for cells incubated with the radioactive isotope for 1 hour and then transferred to a nonradioactive medium. 
TABLE III

Incorporation of $F e^{59}$ into hemoglobin by bone marrow suspensions

\begin{tabular}{|c|c|c|c|c|c|c|c|c|c|}
\hline \multirow[b]{2}{*}{ Patient } & \multirow[b]{2}{*}{ Diagnosis } & \multirow[b]{2}{*}{$\mathrm{Hb}$} & \multirow[b]{2}{*}{ Hct } & \multirow[b]{2}{*}{ Retic } & \multirow[b]{2}{*}{$\mathrm{Hb} \mathrm{A}_{2}$} & \multirow{2}{*}{$\begin{array}{l}\text { Incu- } \\
\text { bation } \\
\text { time }\end{array}$} & \multicolumn{2}{|c|}{ Specific activity } & \multirow{2}{*}{$\begin{array}{r}\text { Ratio } \\
\text { SA A/A }\end{array}$} \\
\hline & & & & & & & $\mathrm{Hb} \mathrm{A}$ & $\overline{\mathrm{Hb} \mathrm{A}}$ & \\
\hline & & $\mathrm{g} / 100 \mathrm{ml}$ & $\%$ & $\%$ & $\%$ & hours & \multicolumn{2}{|c|}{$c p m / m g$} & \\
\hline \multicolumn{2}{|c|}{ Bone marrow suspensions } & & & & & & & & \\
\hline J. W. & Folic acid deficiency & 6.5 & 18.8 & 0.3 & 4.2 & 4.3 & 157 & 128 & 1.1 \\
\hline J. W. & After 7 days of therapy & & 25 & 28 & 3.8 & 4.3 & 538 & 398 & 1.4 \\
\hline M. B. & Pernicious anemia & & 16.1 & 1.9 & & 5 & 72 & 58 & 1.2 \\
\hline J. H. & Pneumococcol pneumonia & 1.11 & 34 & 8.1 & & 5.5 & 1.6 & 1.2 & 1.3 \\
\hline
\end{tabular}

moved after 1 hour of incubation, washed with $0.85 \% \mathrm{NaCl}$, and then placed in an incubation medium containing nonradioactive ferrous sulfate equilibrated with human serum. Incubation was then continued for 4 more hours. As seen in Figure 4 there was no drop in the specific activity of hemoglobins $\mathrm{S}$ or $\mathrm{A}_{2}$. This indicates that no significant exchange of iron occurred between hemoglobin and the medium.

Incorporation of $F e^{59}$ into hemoglobins $A$ and $A_{2}$ by bone marrow in vitro. The results of four experiments in which bone marrow samples were incubated with $\mathrm{Fe}^{59}$ are indicated in Table III. Concentration of the nucleated cells by centrifugation was not attempted. In each case the specific activity of hemoglobin $\mathrm{A}$ was slightly greater than that of hemoglobin $A_{2}$. However, the ratios of the specific activities were much closer to unity than those found for experiments employing reticulocytes.

Incorporation of leucine-C $C^{14}$ into hemoglobins $A$ and $A_{2}$ by erythrocyte precursors in vitro. $\mathrm{A}$ series of experiments was done with leucine-C $\mathrm{C}^{\mathbf{1 4}}$ as the radioactive tracer. In each case nonhemoglobin proteins were removed by column chromatography before separation of the hemoglobin fractions. Table IV shows the incorporation into hemoglobins $A$ and $A_{2}$ by reticulocytes. The specific activity of hemoglobin $\mathrm{A}$ was two to three times that of hemoglobin $\mathrm{A}_{2}$ at incubation times ranging from 2 to 5 hours. In each experiment, however, no difference in the specific activities of the two hemoglobins was seen after very short periods of incubation (Figure 5).

Table IV shows the results of an experiment in which reticulocytes were incubated in modified Krebs-Henseleit solution from which leucine had not been excluded. The ratios of the specific activities of hemoglobins $A$ and $A_{2}$ were the same as in experiments in which leucine was excluded.

Table IV also shows the results of an experiment in which bone marrow was incubated with leucine- $\mathrm{C}^{14}$. The ratio of the specific activities of hemoglobins $A$ and $A_{2}$ was much closer to unity

TABLE IV

Incorporation of leucine- $C^{14}$ into hemoglobin by reticulocytes and bone marrow in vitro

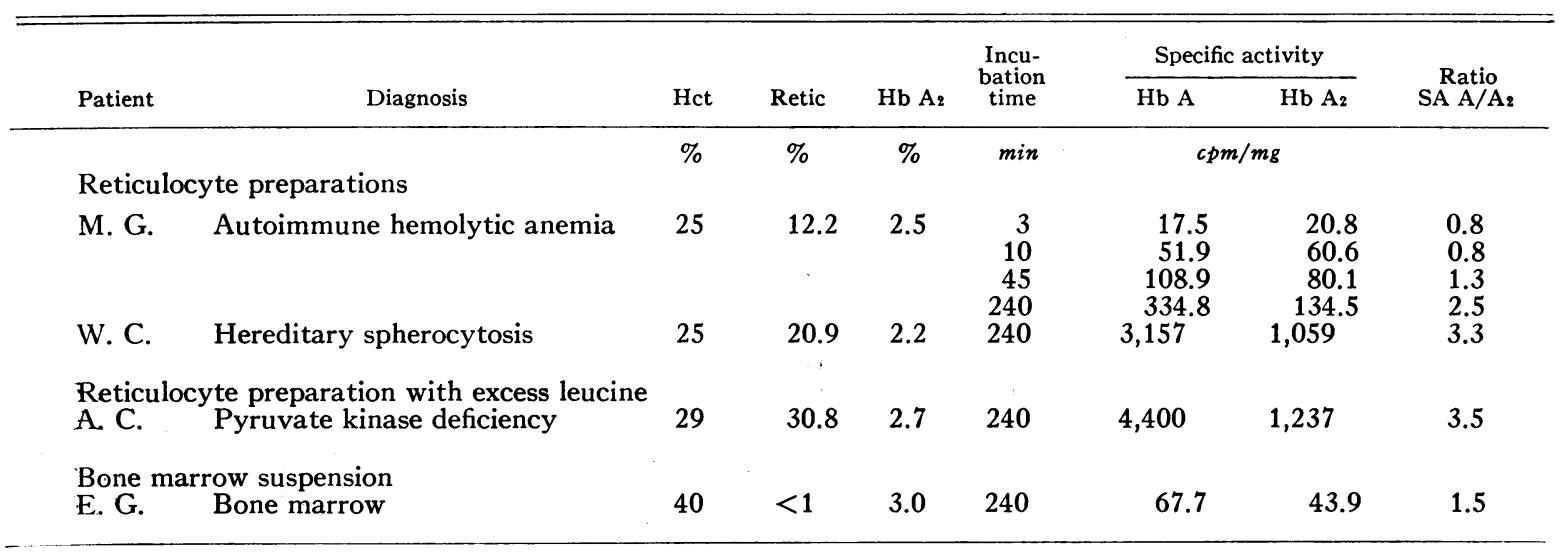



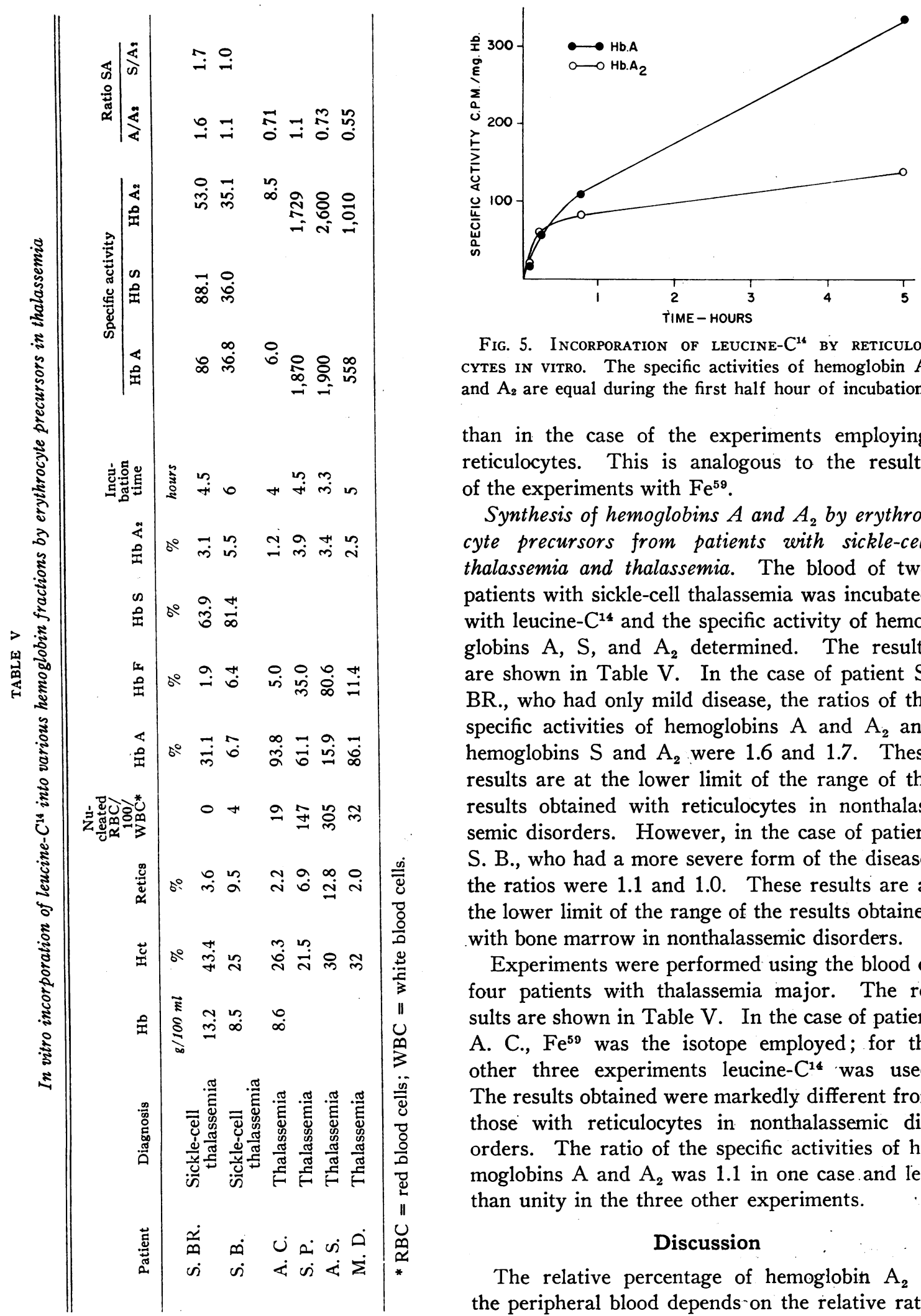

Fig. 5. INCORPORATION OF LEUCINE-C $C^{14}$ BY RETICULOCYTES IN vitro. The specific activities of hemoglobin A and $A_{2}$ are equal during the first half hour of incubation.

than in the case of the experiments employing reticulocytes. This is analogous to the results of the experiments with $\mathrm{Fe}^{59}$.

Synthesis of hemoglobins $A$ and $A_{2}$ by erythrocyte precursors from patients with sickle-cell thalassemia and thalassemia. The blood of two patients with sickle-cell thalassemia was incubated with leucine- $\mathrm{C}^{14}$ and the specific activity of hemoglobins $A, S$, and $A_{2}$ determined. The results are shown in Table $V$. In the case of patient $S$. $B R$., who had only mild disease, the ratios of the specific activities of hemoglobins $A$ and $A_{2}$ and hemoglobins $\mathrm{S}$ and $\mathrm{A}_{2}$ were 1.6 and 1.7. These results are at the lower limit of the range of the results obtained with reticulocytes in nonthalassemic disorders. However, in the case of patient S. B., who had a more severe form of the disease, the ratios were 1.1 and 1.0. These results are at the lower limit of the range of the results obtained with bone marrow in nonthalassemic disorders.

Experiments were performed using the blood of four patients with thalassemia major. The results are shown in Table V. In the case of patient A. C., $\mathrm{Fe}^{50}$ was the isotope employed; for the other three experiments leucine- $\mathrm{C}^{\mathbf{1 4}}$ was used. The results obtained were markedly different from those with reticulocytes in nonthalassemic disorders. The ratio of the specific activities of hemoglobins $A$ and $A_{2}$ was 1.1 in one case and less than unity in the three other experiments.

\section{Discussion}

The relative percentage of hemoglobin $A_{2}$ in the peripheral blood depends on the relative rates 
of synthesis and destruction of the major and minor hemoglobin components. Decreased synthesis of hemoglobin $\mathrm{A}_{2}$ occurs in individuals with hereditary persistence of fetal hemoglobin (8). In patients with hemoglobin Zürich the elevated level of hemoglobin $A_{2}$ appears to be a reflection of loss of unstable hemoglobin Zürich (6). In thalassemia minor the increased percentage of hemoglobin $\mathrm{A}_{2}$ in the peripheral blood is probably due to a combination of increased hemoglobin $\mathrm{A}_{2}$ synthesis and decreased hemoglobin A production (17). The cause of the changes in hemoglobin $A_{2}$ levels in pernicious anemia and iron deficiency anemia is not known (5). Except for studies in thalassemic individuals (18), little is known about the relative survival times of hemoglobins $\mathrm{A}$ and $\mathrm{A}_{2}$ in various hematologic disorders.

In the present study reticulocytes were obtained from individuals with a variety of hematologic disorders affecting erythrocyte production. Synthesis of hemoglobins $\mathrm{A}$ and $\mathrm{A}_{2}$ by reticulocytes was measured in vitro by determining the rates of incorporation of $\mathrm{Fe}^{59}$ or leucine- $\mathrm{C}^{14}$ into the two protein fractions. With reticulocytes from patients with disorders other than thalassemia, the results of all experiments except one were quite similar. The specific activity of hemoglobin $\mathrm{A}_{2}$ was consistently less than that of hemoglobin $A$ at periods of incubation ranging from 4 to 22 hours. At shorter incubation times this difference was much less marked. In experiments in which bone marrow was incubated under similar conditions the relative specific activities of hemoglobins $A$ and $A_{2}$ were closer to unity, although that of hemoglobin $A$ was slightly higher than that of hemoglobin $A_{2}$. In experiments utilizing blood from individuals with thalassemia major the ratio of the specific activity of hemoglobin $A$ to hemoglobin $A_{2}$ was less than unity in three of four cases.

It is unlikely that these results are due to a technical artifact. There were no changes in the proportions of hemoglobins $\mathrm{A}$ and $\mathrm{A}_{2}$ during incubation. Nonhemoglobin proteins were removed by column chromatography, and each fraction was further purified by starch block and starch gel electrophoresis. The contamination of hemoglobin $\mathrm{A}$ by a nonhemoglobin protein with identical electrophoretic and chromatographic charac- teristics is possible but unlikely since, in experiments utilizing blood from individuals with sicklecell anemia, the specific activity of hemoglobin $A_{2}$ was also less than that of hemoglobin S. No evidence of exchange between radioactive iron in hemoglobin $\mathrm{A}$ or $\mathrm{A}_{2}$ and the incubation medium was found. Modifications of the relative rates of synthesis of hemoglobins $A$ and $A_{2}$ due to relatively low concentrations of iron or leucine in the incubation mixture are unlikely, particularly in the experiments utilizing leucine, because of the large quantities of radioactive leucine that were added to the mixture. In addition similar results were obtained in an experiment utilizing excess leucine in the incubation mixtures.

Differences in the relative specific activities of hemoglobins $A$ and $A_{2}$ could result from differences in their carrier pool sizes. A similar explanation has been invoked to explain the lower specific activity of hemoglobin $\mathrm{F}$ as compared with hemoglobin $\mathrm{A}$ in the blood of individuals with sickle-cell anemia and thalassemia major $(18,19)$. In these conditions the cells containing relatively high concentrations of hemoglobin $\mathrm{F}$ survive longer, and the turnover rate of hemoglobin $F$ is consequently lower. Similar differences in specific activity of hemoglobins $\mathrm{A}$ and $\mathrm{F}$ in blood obtained from thalassemic individuals have been found after in vitro incubation of reticulocytes with radioactive amino acids $(20,21)$. In the present experiments, however, such variation in carrier pool is very unlikely, since at early times of incubation with both radioactive iron and amino acids, the specific activities of hemoglobins $A$ and $\mathrm{A}_{2}$ were similar. A difference in unlabeled carrier pool size would have resulted in differences in the specific activities at all times of incubation.

Similar specific activities of hemoglobins A and $\mathrm{A}_{2}$ after administration of intravenous $\mathrm{Fe}^{59}$ have been previously reported (22) and are confirmed in the present studies. These results indicate that the two hemoglobins are synthesized in vivo in the proportion found in the peripheral blood. Incubation of bone marrow suspensions with $\mathrm{Fe}^{59}$ or leucine- $\mathrm{C}^{14}$ revealed specific activities for the two fractions that were much closer to unity than in experiments with reticulocytes. These results indicate that hemoglobin $A_{2}$ synthesis terminates before hemoglobin $\mathrm{A}$ synthesis in the reticulocyte. The hemoglobin $\mathrm{A} / \mathrm{A}_{2}$ ra- 
tios of unity or less in blood samples obtained from individuals with thalassemia major probably reflect the large number of nucleated red cells present in the incubation mixture. However, even when bone marrow was diluted with blood containing less than $1 \%$ reticulocytes, the hemoglobin $\mathrm{A} / \mathrm{A}_{2}$ ratio was never less than unity, as was the case in three of four thalassemic blood samples studied. A fundamental difference in the relationship of hemoglobin $A$ to $A_{2}$ synthesis in this disorder as compared with other hematologic states may be an alternative explanation for these findings.

Hemoglobin synthesis in the reticulocytes is almost complete, in vitro incorporation studies of the type presented in this study measuring only the last vestiges of protein synthesis. The results of these experiments indicate that, in reticulocytes, hemoglobin $A_{2}$ synthesis is retarded before that of hemoglobin $A$. The fact that similar results were not obtained in the presence of nucleated red cells suggests that these findings are real and not the result of an artifact of the in vitro incubation system. The mechanism by which hemoglobin synthesis in "turned off" in the reticulocyte has not been worked out. The in vitro differences in the retardation of hemoglobins $A$ and $A_{2}$ synthesis may provide a model for the further study of these mechanisms.

\section{Summary}

The incorporation of both radioactive iron and amino acids into hemoglobins $\mathrm{A}$ and $\mathrm{A}_{2}$ in an in vitro system has been studied. In reticulocyte preparations the specific activity of hemoglobin A always exceeds that of hemoglobin $\mathrm{A}_{2}$ at incubation times of greater than 2 hours, whereas at earlier times, this difference is less marked. The difference is also less in experiments utilizing bone marrow and blood from individuals with thalassemia major. These results indicate that, in the reticulocyte, hemoglobin $A_{2}$ synthesis is retarded before that of hemoglobin $\mathrm{A}$.

\section{References}

1. Kunkel, H. G., and A. G. Bearn. Minor hemoglobin components of normal human blood. Fed. Proc. 1957, 16, 760.

2. Goldstein, M. A., N. Patpongpanij, and V. Minnich. The incidence of elevated hemoglobin $A_{2}$ levels in the American Negro. Ann. intern. Med. 1964, 60, 95.

3. Kunkel; H. G., R. Ceppellini, U. Müller-Eberhard, and $\mathrm{J}$. Wolf. Observations on the minor basic hemoglobin component in the blood of normal individuals and patients with thalassemia. J. clin. Invest. 1957, 36, 1615.

4. Gerald, P. S., and L. K. Diamond. The diagnosis of thalassemia trait by starch block electrophoresis of the hemoglobin. Blood 1958, 13, 61.

5. Josephson, A. M., M. S. Masri, L. Singer, D. Dworkin, and K. Singer. Starch block electrophoretic studies of human hemoglobin solutions. II. Results in cord blood, thalassemia and other hematologic disorders: comparison with Tiselius electrophoresis. Blood 1958, 13, 543.

6. Rieder, R. F., W. H. Zinkham, and N. A. Holtzman. Hemoglobin Zürich: clinical, chemical and kinetic studies. In preparation.

7. Wheeler, J. T., and J. R. Krevans. The homozygous state of persistent fetal hemoglobin and the interaction of persistent fetal hemoglobin with thalassemia. Bull. Johns Hopk. Hosp. 1961, 109, 217.

8. Conley, C. L., D. J. Weatherall, S. N. Richardson, M. K. Shepard, and S. Charache. Hereditary persistence of fetal hemoglobin: a study of 79 affected persons in 15 Negro families in Baltimore. Blood 1963, 21, 261.

9. King, E. J., and M. Gilchrist. Determination of hæmoglobin. 1. Determination by a cyan-hæmatin method. Lancet 1947, 2, 201.

10. Borsook, H. Hemoglobin synthesis in vitro in rabbit reticulocytes in Conference on Hemoglobin, Washington, National Academy of SciencesNational Research Council, 1958, p. 111.

11. Allen, D. W., W. A. Schroeder, and J. Balog. Observations on the chromatographic heterogeneity of normal adult and fetal human hemoglobin: a study of the effects of crystallization and chromatography on the heterogeneity and isoleucine content. J. Amer. chem. Soc. 1958, 80, 1628.

12. Schnek, A. G., and W. A. Schroeder. The relation between the minor components of whole normal human adult hemoglobin as isolated by chromatography and starch block electrophoresis. J. Amer. chem. Soc. 1961, 83, 1472.

13. Smithies, O. An improved procedure for starch-gel electrophoresis: further variations in the serum proteins of normal individuals. Biochem. J. 1959, 71, 585.

14. Poulik, M. D. Starch gel electrophoresis in a discontinuous system of buffers. Nature (Lond.) 1957, 180, 1477.

15. Vinograd, J., and W. D. Hutchinson. Carbon-14 labelled hybrids of hæmoglobin. Nature (Lond.) 1960, 187, 216.

16. Greenough, W. B., III, T. Peters, Jr., and E. D. Thomas. An intracellular protein intermediate 
for hemoglobin formation. J. clin. Invest. 1962, 41, 1116.

17. Baglioni, C. Correlations between genetics and chemistry of human hemoglobins in Molecular Genetics, J. H. Taylor, Ed. New York, Academic Press, 1963, p. 405.

18. Gabuzda, T. G., D. G. Nathan, and F. H. Gardner. The turnover of hemoglobins $A, F$, and $A_{2}$ in the peripheral blood of three patients with thalassemia. J. clin. Invest. 1963, 42, 1678.

19. Singer, K., and B. Fisher. Studies on abnormal hemoglobins. V. The distribution of type S (sickle cell) hemoglobin and type F (alkali resistent) hemoglobin within the red cell population in sickle cell anemia. Blood 1952, 7, 1216.

20. Marks, P. A., and E. R. Burka. Hemoglobins A and $\mathrm{F}$ : formation in thalassemia and other hemolytic anemias. Science 1964, 144, 552.

21. Weatherall, D. J., and M. A. Naughton. Unpublished data.

22. Ranney, H. M., and P. Kono. Studies of the incorporation of $\mathrm{Fe}^{59}$ into normal and abnormal hemoglobins. J. clin. Invest. 1959, 38, 508. 